\title{
Estimating Spatial Effects of Transport Infrastructure on Agricultural Output of Iran
}

\author{
Nastaran Najkar ${ }^{1}$, Mohammad Reza Kohansal², Mohammad Ghorbani² \\ ${ }^{1}$ Department of Agricultural Economics, International Campus of Ferdowsi University of Mashhad, Iran \\ ${ }^{2}$ Department of Agricultural Economics, Ferdowsi University of Mashhad, Iran
}

\begin{abstract}
This paper examines the possibility of spatial spillover effects of transport infrastructure in Iran provinces. We estimate the regional spillovers of the transport infrastructure stock by applying a spatial Durbin model from 1980-2015. The results indicate that positive spillover effect exist due to the connectivity characteristic of transport infrastructure at the national level. A spatial Durbin model that obtains spatial dependence in a given province has a positive direct effects on agricultural output. Also, at the national level, the spillover effect of road infrastructure on elasticity of output in neighboring provinces varies with respect to the spatial weight matrix used in the spatial Durbin model. Moreover, our analysis shows that enhancement in road infrastructure in the provinces, south region shows a larger positive spillover effect on agricultural output when compared to central or west provinces. At the regional level, transport infrastructure spillover effects change significantly all the time among Iran's five macro-regions.
\end{abstract}

\section{Keywords}

Spatial Durbin model, agricultural production, spillover effect, transport infrastructure.

Najkar, N., Kohansal, M. R. and Ghorbani, M. (2018) "Estimating Spatial Effects of Transport Infrastructure on Agricultural Output of Iran", A GRIS on-line Papers in Economics and Informatics, Vol. 10, No. 2, pp. 61-71. ISSN 1804-1930. DOI 10.7160/aol.2018.100206.

\section{Introduction}

Investment in roads and improved road connectivity positively affect agricultural productivity and output. Such evidence includes econometric analysis of subnational data on the positive effects of public investments on agricultural output in the China and India (Fan and Hazell, 2001). The discussion of the economic impact of public infrastructure expanded significantly following a series of papers by Aschauer (1989), who argued that enhancing infrastructure investment will improve regions in achieving their economic potentials. Munnell and cook (1990) considered the relationship between pubic capital and economic performance at the national and state level. The output elasticity of public capital stock was found to be 0.15 and with highway alone contributing 0.06 . Transportation infrastructure may have a positive effect on regional economic growth because the benefits generated from the infrastructure might not be limited to that specific region (Moreno and López-Bazo, 2007). To test the hypothesis empirically, different types of spatial models have been adopted (Cohen and Morrison Paul, 2004). However, because of the different focuses of each study, there is no consistent conclusion on whether spillover effects of transportation infrastructure are positive or even exist at a significant level. Boarnet (2002) constructed a spatial lag model in a Cobb-Douglas production function form to investigate the spatial effects of public infrastructure (roads and highways) in California counties. His study found a negative spatial lag effect for California road systems, which he believed was caused by migration. By relying on panel data for the 48 contiguous states over the years from 1969 to 1986, Holtz-Eakin and Schwartz (1995) found that highway stocks do not have important spillover effects on private productivity. They found the estimation results are sensitive to model specification. A negative effect of highway stock is also found when introducing a variable representing the investments made in counties located further away from the investment location (Ozbay et al., 2007). The theoretical motivation of this study is to follow the path of the new economic geography theory in testing for spillover effects of public transportation infrastructure under a systematic spatial econometric 
approach. As Fingleton and López-Bazo (2006) pointed out, many regional studies externalities in a somewhat often fails to consider the causes of externalities. The diversity of empirical results of the literature on the regional effects of public capital on private sector performance could, at least partially, be explained by the fact that they ignore spillover effects of public capital across regions. In fact, spillover effects should not be ignored when investigating the effects of public capital on private sector performance at the regional level, since public capital installed in one region might well have positive impact on the production of other regions. In other words, public capital in other regions could induce better accessibility of a region to the rest of country (Pereira and Andraz, 2006). Pereira and Roca-Sagalés (2003) and Pereira and Andraz (2006) found positive spillover effects of public capital for almost all regions for Spain and Portugal, respectively. The positive spillover effects arise from network effects from transport infrastructure. Since economic activities in different regions are spatially connecting, economic effects can diffuse through the transport network. Providing a new link or upgrading an existing link not only improve accessibility of the investment region, but also improve accessibility of other regions involved in the transport network. In a spatial econometric framework, positive spillover effects were confirmed by Cantos et al. (2007). Using US state-level data on highways, Jiwattanakalpaisarn et al. (2010) provide evidence of positive output spillovers from highway infrastructure in immediately adjacent more distant states. However, some studies found no clear evidence of positive linkage between public capital formation and private sector output at the regional level for some countries (Pereira and Roca-Sagalés, 2001). Our study aims to evaluate for the presence of regional spillovers of transport investment and to measure their magnitude both in the country as a whole and in specific parts of Iran. However, most of these studies do not estimate spillover effects subnational level, which would be more useful for the public decision making on the planning for large transport projects. Particular emphasis in this paper is the regional difference in the spatial effects of transport infrastructure on agricultural output. This paper attempts to contribute to the literature by examining the existence links between transport infrastructure investment and agricultural production in the state-level agricultural output of Iran. The structure of the paper is as follows. At the first section introduces the methodology and database to quantify spatial spillovers of transport investment in the Iran provinces, and it also presents the results. To improve our understanding of the regional differences in spillover, a deeper analysis of the changes in spillover effects of transport infrastructure among Iran five macro regions will be presented in the next section.

\section{Materials and methods}

In order to assess the role of different forms of infrastructures in regional economic performance, the empirical strategy pursued in this paper starts with a base line model, where the relationship between infrastructure and economic performance is modeled with a Cobb-Douglas production function. Our empirical strategy was to consider the production function as benchmark and then proceed with a specific approach by extending the empirical model with spatial interaction effect (Elhorst, 2013; Lesage and Pace, 2009). Therefore, the baseline empirical model is defined by the following equation:

$$
Y_{i t}=e m p p_{i t}^{\beta E m} K_{i t}^{\beta k} e_{i t}^{\beta e} L_{i t}^{\beta 1} R_{i t}^{\beta r} E_{i t}^{\beta e x} G D P_{i t}^{\beta g}
$$

The SDM, which is the basis for the empirical analysis of equation 1 , is of the form:

$Y=\alpha \kappa+\rho W y+X \beta+\theta W X+\varepsilon$

Where $Y$ is agricultural output; $i$ and $t$ are the indices of province and year respectively, where $\mathrm{W}$ is a contiguity matrix based on the inverse of geographical distance, $\rho$ is the spatial lag (SAR) coefficient, $\mathrm{X}$ is the matrix of control variables, which include, $\theta$ is the vector of coefficient estimates associated with the spatially lagged independent variables and $\kappa$ is a vector of ones. The SDM includes a spatial lag of the dependent variable as well as spatial lagged explanatory variables. Our empirical mode is thus:

$$
\begin{aligned}
\ln \mathrm{y}_{\mathrm{it}} & =\rho \sum_{\mathrm{j}=1}^{\mathrm{N}} \mathrm{W}_{\mathrm{ij}} \ln _{\mathrm{jt}}+\alpha_{0}+\alpha_{1} \ln \text { employment }_{\mathrm{it}} \\
& +\alpha_{2} \ln \text { Capital }_{\mathrm{it}}+\alpha_{3} \ln \text { energy }_{\mathrm{it}}+\alpha_{4} \ln _{\text {Land }} \mathrm{it}_{\mathrm{it}} \\
& +\alpha_{5} \ln \text { Road Stock }+\alpha_{6} \ln \text { Export } \alpha_{7} \ln \text { GDP } \\
& +\gamma_{1} \sum_{\mathrm{j}=1}^{\mathrm{N}} \mathrm{W}_{\mathrm{ij}} \ln \text { employment }+\gamma_{2} \sum_{\mathrm{j}=1}^{\mathrm{N}} \mathrm{W}_{\mathrm{ij}} \text { Capital }_{\mathrm{it}} \\
& +\gamma_{3} \sum_{\mathrm{j}=1}^{\mathrm{N}} \mathrm{W}_{\mathrm{ij}} \text { energy }_{\mathrm{it}}+\gamma_{4} \sum_{\mathrm{j}=1}^{\mathrm{N}} \mathrm{W}_{\mathrm{ij}} \text { Land }_{\mathrm{it}}
\end{aligned}
$$




$$
\begin{aligned}
& +\gamma_{5} \sum_{\mathrm{j}=1}^{\mathrm{N}} \mathrm{W}_{\mathrm{ij}} \text { Road Stock }_{\mathrm{it}}+\gamma_{6} \sum_{\mathrm{j}=1}^{\mathrm{N}} \mathrm{W}_{\mathrm{ij}} \text { Export }_{\mathrm{it}}{ }^{\mathrm{N}} \\
& +\gamma_{7} \sum_{\mathrm{j}=1}^{\mathrm{N}} \mathrm{W}_{\mathrm{ij}} \mathrm{GDP}_{\mathrm{it}}+\mathrm{e}_{\mathrm{it}}
\end{aligned}
$$

The SDM specification allows for spatial effects arising from the SAR of the dependent variable, the explanatory variables and a contagion effect:

$$
y=(1-\rho W)^{-1}(\alpha \kappa+X \beta+\theta W X+\varepsilon)
$$

The SDM is a general spatial model, which, in a restricted form, can be interpreted as a SAR model or SEM. The choice of this unconstrained specification was driven by LM tests and LR tests. The LR tests are each based on a restriction: in the quation 2 , the first restriction, " $\theta=0$ ", which corresponds to the case of the SAR model; then, we tested a second restriction, the so-called common factor restriction (" $\rho \beta+\theta=0 ")$, which implies the SEM. In particular, the SEM specification arises when the common factor restriction holds and spatial interaction among units of observation is spatial dependence in the disturbance process (Lesage and Pace, 2009). According to Lesage and pace (2009), the SDM specification contains spatially lagged values of both the dependent and the explanatory variables. They provided the theoretical framework to interpret these direct and indirect effects, by transforming the spatial weight matrix and considering the role of off and on diagonal elements. Inference of these measures was calculated, we apply Maximum likelihood (ML) in estimating spatial panel data models. The spatial panel model can be computed by the spatial econometrics library for MATLAB provided by Lesage. In this the study, we follow the Elhorst (2012) spatial model testing procedure to test which spatial model is preferred technically. Although Lagrange multiplier (LM) test shows a spatial lag model is preferred, the general test (LR test) recommends that a spatial Durbin model is more efficient. To provide a comprehensive view to robustness, estimations of both a spatial lag model and a spatial error model are summarized in the final results. The LR test results, as displayed in the Table 2, exhibit that both spatial fixed effect and time fixed effect are jointly significant. The spatial order rook contiguity weight matrix was constructed in a similar way (Haandrikman et al., 2010) but it also takes the neighbors of neighbors into account.

\section{Data collection}

The data used in this research are collected from a number of different from Iran sources, including the period from (1980-2015) the statistical Yearbook of Iran provinces. Data on transportation infrastructure include road investment. Transport investment (Road) data were generated from the Highway Statistics series published by the Management and Planning Government of Iran (MPO), and includes the investment outlay on interstate highway systems, other road and streets, and maintenance services. The index of agricultural output data $(Y)$ is generated by physical quantities and market prices of crops that these data have been taken from Agricultural Statistical Yearbook. The index of capital input is determined from the provincial capital stock, while the index of employment input includes working hours of labor. The index of energy input consists of fuel consumption for agriculture sector. The index of land input measures the intertemporal price index of the land. The capital, energy and land data have been provided from Iran Statistical Yearbook. The data of Karaj is combined with those of Tehran province until 2006. We use data from a panel of 30 Iran provinces for the period 1980-2015 on agricultural output, capital, employs labor, energy, land, transport infrastructure investment and public investment, export, and gross domestic production (GDP). The descriptive each statistics of each variable are summarized in the Table 1.

\begin{tabular}{|l|c|c|c|c|}
\hline Variables & Mean & Std.dev. & Min & Max \\
\hline Capital & 37.26 & 0.54 & 12 & 63.6 \\
\hline empolyment & 7.73 & 0.32 & 1.9 & 14.2 \\
\hline energy & 45.87 & 0.78 & 16.5 & 76.8 \\
\hline Land & 31.15 & 1.05 & 11.8 & 40.8 \\
\hline Road Stock & 44.97 & 1.63 & 28 & 65.2 \\
\hline Export & 30.96 & 0.84 & 18 & 45.6 \\
\hline GDP & 10.91 & 0.62 & 9.6 & 14.7 \\
\hline
\end{tabular}

Source: own processing

Table 1: Summary statistics of variables in logs.

\section{Results and discussion}

In order to compare the changes of the spillover effects over time, we also ran the spillover effects over time, and the next section we also ran the spillover effects model for three sub-times, 1980-1991, 1992-2003, and 2004-20015, respectively. The key results at the national and regional levels are presented in the Table 2, 3, 4 . In this study, statistical significance at the 5\% level; those variables and test statistics are henceforth 
referred to as significant in the discussion below.

\section{Spillover effects at the national level}

The results for the model 1 in the Table 2 show that labor, land, and energy affect a state's agricultural output. An increase in road disbursement has significant effect on agricultural output. However, the model 4 does not capture the spatial interaction effects among variables, which may produce biased estimations. This study adopted the bias-correction method proposed by Lee and Yu (2010) to capture unbiased estimator in the presence of spatial and time period fixed effects. The Table 2 displays estimation results of the regional impacts of total public transportation infrastructure from OLS with fixed effect, SEM, SAR, and SDM with spatial fixed effect. The null hypothesis of the LR test for joint significance of spatial fixed effects is rejected, as a result the model should include spatial fixed effects (SDM). In the non-spatial model, the general impact of transportation infrastructure is 0.051 , which is lower than the result in SDM, SEM and SAR. The spatial lags of independent variables are highly statistically significant in the SDM model the Table 2 except spatial lag of GDP. Spatial lag of employment and energy is found to be the most important factor for agricultural output. The result of the SDM model show that capital, energy, road stock affect a province's agricultural output. The direct and spillover effects of the parameters using the decomposition approach discussed in the methodology section were estimated with four different neighbor contiguity in the Table 3. The results show that spillover effect of private capital has positive and significant effect at the $5 \%$ level for the second nearest neighbor. The total effect of employment is 0.37 indicates that employment play a key role in agricultural output under second nearest neighbor. Land was observed to have a negative and significant total effect on agricultural output. The direct and spillover effects of land on agricultural production is negative under all weight matrices. This negative impact may result from productivity growth indicating that less land are required to increase agricultural production (Ball et al., 1997). In terms of spillover effect comparison, the road stock variable has both significant and positive direct and indirect effects. The spillover effect of road output elasticity is 0.16 , which exhibits that an one percent increase in highway infrastructure is associated with a 0.16 percent increase in agricultural output at the second order of contiguity neighbor. This finding implies that instead of a negative spillover effects (Boarnet, 2002), public highway infrastructure has a positive spillover effects on output elasticity. The Table 3 also indicates that a $1 \%$ increase in energy input in a province increases agricultural output by $0.20-0.38 \%$ using second nearest neighbor. As hypothesized, a statistically significant spillover effect of road infrastructure is found. However,

\begin{tabular}{|c|c|c|c|c|}
\hline & SDM & SEM & SAR & Pooled OLS \\
\hline & Spatial Fixed & Spatial Fixed & Spatial Fixed & Fixed effects \\
\hline Capital & $0.195(0.01)^{*}$ & $0.174(0.00)^{*}$ & $0.166(0.00)^{*}$ & $0.188(0.00)^{*}$ \\
\hline employment & $0.343(0.01)^{*}$ & $0.284(0.00)^{*}$ & $0.292(0.05)^{*}$ & $0.303(0.01)^{*}$ \\
\hline energy & $0.315(0.00)^{*}$ & $0.317(0.00)^{*}$ & $0.332(0.00)^{*}$ & $0.326(0.00)^{*}$ \\
\hline Land & $-0.126(0.00)^{*}$ & $-0.104(0.01)^{*}$ & $-0.112(0.00)^{*}$ & $-0.108(0.00)^{*}$ \\
\hline Road Stock & $0.071(0.01)^{*}$ & $0.063(0.00)^{*}$ & $0.058(0.00)^{*}$ & $0.051(0.04)^{*}$ \\
\hline Export & $0.095(0.21)$ & $0.091(0.00)^{*}$ & $0.098(0.31)$ & $0.096(0.06)$ \\
\hline GDP & $0.086(0.04)^{*}$ & $0.081(0.08)$ & $0.078(0.01)^{*}$ & $0.076(0.05)^{*}$ \\
\hline Capital.splag & $0.126(0.05)^{*}$ & $0.119(0.04)^{*}$ & $0.125(0.01)^{*}$ & $0.128(0.00)^{*}$ \\
\hline employment.splag & $0.351(0.01)^{*}$ & $0.286(0.00)^{*}$ & $0.348(0.12)$ & $0.361(0.03)^{*}$ \\
\hline Energy.splag & $0.327(0.00)^{*}$ & $0.291(0.04)^{*}$ & $0.327(0.07)$ & $0.376(0.01)^{*}$ \\
\hline Land.splag & $-0.083(0.01)^{*}$ & $0.079(0.12)$ & $-0.081(0.00)^{*}$ & $0.086(0.10)$ \\
\hline Road Stock.splag & $0.119(0.03)^{*}$ & $0.126(0.00)^{*}$ & $0.124(0.02)^{*}$ & $0.117(0.00)^{*}$ \\
\hline Export.splag & $0.065(0.05)^{*}$ & $0.071(0.16)$ & $0.068(0.09)$ & $0.074(0.04)^{*}$ \\
\hline GDP.splag & $0.074(0.12)$ & $0.079(0.04)^{*}$ & $0.081(0.01)^{*}$ & $0.083(0.26)$ \\
\hline LR Spatial fixed effects test & $1750(0.00)^{*}$ & & & \\
\hline LR Time period fixed effects test & $312.06(0.00)^{*}$ & & & \\
\hline
\end{tabular}

Note: P-value is in parenthesis.*Statistical significance at the 5\% level.

Source: own processing

Table 2: Estimation results of panel data with spatial interaction effects. 


\begin{tabular}{|c|c|c|c|c|c|c|}
\hline \multirow[b]{2}{*}{ Spatial weight matrix } & \multicolumn{2}{|c|}{ Direct effect } & \multicolumn{2}{|c|}{ Indirect effect } & \multicolumn{2}{|c|}{ Total effect } \\
\hline & Coef & P-Value & Coef & P-Value & Coef & P-Value \\
\hline \multicolumn{7}{|l|}{ Nearest neighbor 1} \\
\hline Capital x W & 0.141 & $(0.00)^{*}$ & 0.125 & $(0.05)^{*}$ & 0.196 & $(0.00)^{*}$ \\
\hline employment $\mathrm{x} \mathrm{W}_{1}$ & 0.227 & $(0.04)^{*}$ & 0.329 & $(0.00)^{*}$ & 0.389 & $(0.01)^{*}$ \\
\hline energy $\mathrm{x} \mathrm{W}_{1}$ & 0.246 & $(0.05)^{*}$ & 0.316 & $(0.03)^{*}$ & 0.393 & $(0.01)^{*}$ \\
\hline Land $\mathrm{x}_{1}$ & -0.105 & $(0.00)^{*}$ & -0.098 & $(0.00)^{*}$ & -0.146 & $(0.05)^{*}$ \\
\hline Road Stock x W & 0.114 & $(0.15)$ & 0.104 & $(0.24)$ & 0.179 & $(0.06)$ \\
\hline Export x $\mathrm{W}_{1}$ & 0.086 & $(0.00)^{*}$ & 0.094 & $(0.02)^{*}$ & 0.125 & $(0.14)$ \\
\hline $\begin{array}{l}\mathrm{GDP} \times \mathrm{W}_{1} \\
\text { Nearest neighbor } 2\end{array}$ & 0.075 & $(0.04)^{*}$ & 0.106 & $(0.26)$ & 0.125 & $(0.05)^{*}$ \\
\hline Capital x W & 0.069 & $(0.03)^{*}$ & 0.086 & $(0.00)^{*}$ & 0.115 & $(0.05)^{*}$ \\
\hline employment $\mathrm{x} \mathrm{W}_{2}$ & 0.217 & $(0.03)^{*}$ & 0.278 & $(0.21)$ & 0.386 & $(0.24)$ \\
\hline energy $x \mathrm{~W}_{2}$ & 0.209 & $(0.19)$ & 0.337 & $(0.01)^{*}$ & 0.385 & $(0.01)^{*}$ \\
\hline Land $\mathrm{x} \mathrm{W}_{2}$ & -0.075 & $(0.01)^{*}$ & -0.125 & $(0.04)^{*}$ & -0.106 & $(0.17)$ \\
\hline Road Stock x W ${ }_{2}$ & 0.056 & $(0.00)^{*}$ & 0.166 & $(0.00)^{*}$ & 0.174 & $(0.05)^{*}$ \\
\hline Export $\mathrm{x} \mathrm{W}_{2}$ & 0.046 & $(0.12)$ & 0.091 & $(0.05)^{*}$ & 0.138 & $(0.00)^{*}$ \\
\hline $\begin{array}{l}\mathrm{GDP} \times \mathrm{W}_{2} \\
\text { Nearest neighbor } 3\end{array}$ & 0.096 & $(0.00)^{*}$ & 0.084 & $(0.09)$ & 0.192 & $(0.00)^{*}$ \\
\hline Capital x W & 0.109 & $(0.00)^{*}$ & 0.145 & $(0.19)$ & 0.214 & $(0.01)^{*}$ \\
\hline employment $\mathrm{x} \mathrm{W}_{3}$ & 0.238 & $(0.25)$ & 0.232 & $(0.01)^{*}$ & 0.397 & $(0.04)^{*}$ \\
\hline energy $\mathrm{x} \mathrm{W}_{3}$ & 0.262 & $(0.01)^{*}$ & 0.256 & $(0.08)$ & 0.465 & $(0.17)$ \\
\hline Land $\mathrm{x} \mathrm{W}_{3}$ & -0.106 & $(0.04)^{*}$ & -0.098 & $(0.00)^{*}$ & -0.127 & $(0.00)^{*}$ \\
\hline Road Stock x W ${ }_{3}$ & 0.102 & $(0.00)^{*}$ & 0.154 & $(0.03)^{*}$ & 0.277 & $(0.00)^{*}$ \\
\hline Export $\mathrm{x} \mathrm{W}_{3}$ & 0.093 & $(0.24)$ & 0.126 & $(0.00)^{*}$ & 0.168 & $(0.09)$ \\
\hline $\begin{array}{l}\mathrm{GDP} \times \mathrm{W}_{3} \\
\text { Nearest neighbor } 4\end{array}$ & 0.104 & $(0.01)^{*}$ & 0.082 & $(0.08)$ & 0.143 & $(0.00)^{*}$ \\
\hline Capital x W ${ }_{4}$ & 0.148 & $(0.02)^{*}$ & 0.108 & $(0.00)^{*}$ & 0.203 & $(0.35)$ \\
\hline employment $\mathrm{x} \mathrm{W}_{4}$ & 0.208 & $(0.08)$ & 0.313 & $(0.03)^{*}$ & 0.401 & $(0.00)^{*}$ \\
\hline energy $\mathrm{x} \mathrm{W}_{4}$ & 0.256 & $(0.05)^{*}$ & 0.222 & $(0.15)$ & 0.468 & $(0.08)$ \\
\hline Land $\mathrm{x} \mathrm{W}_{4}$ & -0.043 & $(0.00)^{*}$ & -0.064 & $(0.04)^{*}$ & -0.096 & $(0.14)$ \\
\hline Road Stock x W ${ }_{4}$ & 0.104 & $(0.01)^{*}$ & 0.115 & $(0.05)^{*}$ & 0.148 & $(0.04)^{*}$ \\
\hline Export $\mathrm{x} \mathrm{W}_{4}$ & 0.054 & $(0.07)$ & 0.087 & $(0.03)^{*}$ & 0.135 & $(0.00)^{*}$ \\
\hline $\mathrm{GDP} \mathrm{W}_{4}$ & 0.076 & $(0.14)$ & 0.107 & $(0.25)$ & 0.116 & $(0.00)^{*}$ \\
\hline
\end{tabular}

Note: P-value is in parenthesis. ${ }^{*}$ Statistical significance at the $5 \%$ level.

Source: own processing

Table 3: Direct and indirect effects of SDM results with different weight matrices.

the significance of spillover effects of road infrastructure on a state's agricultural output is not consisting over the four spatial weight models. When using a spatial weight matrix considering for the all neighbor states, the spillover effect of road stock is not significant effect for order one. However, when the neighboring provinces are extended by including one more layer of adjacent states in the second, and third order, the spillover effect of road disbursement becomes significant. Combining the positive and significant direct and spillover effects of road disbursement under second order, a $1 \%$ increase in road investment in a particular province increases the agricultural output across all provinces by $17 \%$. The significant spillover or total effect of transportation infrastructure on a state's agricultural output are found when further adjacent layer were considered as the forth neighbor states. The spillover effects of Fars and Mazandaran are the largest $(0.18 \%)$, suggesting an improvement in the road investment in these two states respectively would have higher spillover effects on the agricultural output of other provinces based on the estimated parameters using the second nearest neighbor (see Figures $2 \mathrm{a}, \mathrm{b}$ ). 


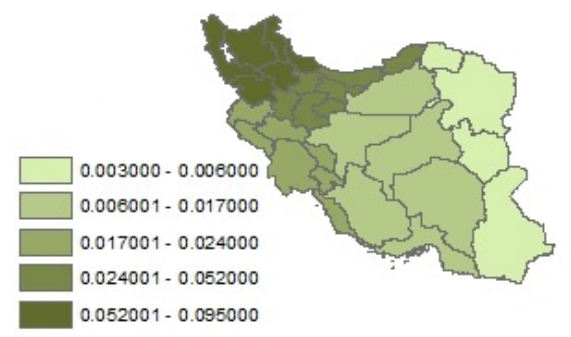

Source: own processing

Figure 1a: The spillover effect from $\% 1$ percent change in road stock in East Azarbaijan province.

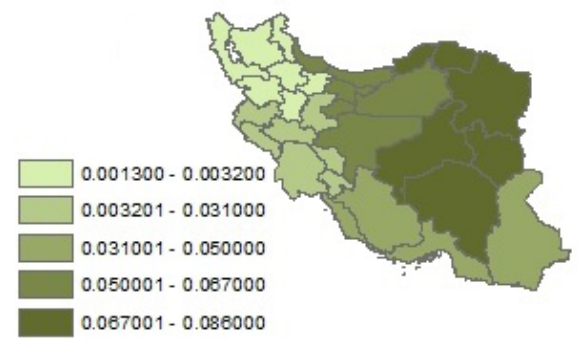

Source: own processing

Figure 1b: The spillover effect from a $\% 1$ change in road stock in Razavi Khorasan province.

The spillover effects of road stocks in Esat Azarbaijan province have relatively low spillover effects on the agricultural output of other provinces because of the geographic location of those provinces. Figure $(1 \mathrm{a}, \mathrm{b})$ show the spillover effects pattern associated with a $1 \%$ increase in road investment in East Azarbaijan and Razavi Khorasan provinces, respectively. Both figures show that the spillover effects extend across through the whole nation but diminish as the order of neighbor increases. The spillover effects of the investment in East Azarbaijan as the order of neighbor increases. The spillover effects of the investment in East Azarbaijan expand to center but decline after the first order neighboring provinces while the spillover effects of the investment in Mazandaran spread out in all directions and stay sustainable until reaching those boundary. The spatial spillover effects of improvements or investment in transportation infrastructure in a given state on the output of other states can be explained as the improvement of efficiency of the inputs (Cohen, 2010) or in the geographical distribution of economic activities (Kemmerling and Stephan, 2008; Duranton and Tunet, 2012). For instance, improved road infrastructure in Mazandaran province can increase the availability of input factors for other agricultural states, Gilan province (nearest province to Mazandaran province) therefore improving production in those provinces. The results in Figures $1 \mathrm{a}, 1 \mathrm{~b}$ and $2 \mathrm{a}, \mathrm{b}$ indicate that the amount and structure of spatial spillover effects. The positive and significant impacts of the spillover effect of road investment found under second nearest neighbor, but not observed under first nearest neighbor" " can be connected to the feature of Iran agriculture. Macro-regions in Iran are shown in the Figure 3.

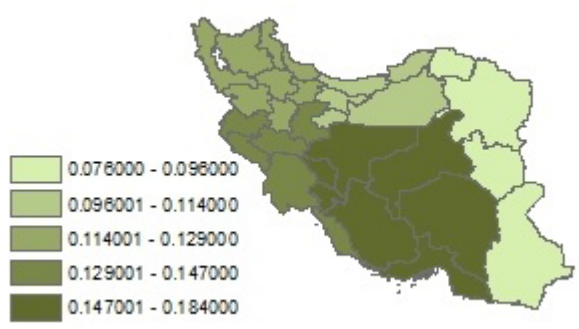

Source: own processing

Figure 2a: The spillover effect with a $\% 1$ change in road stock in Fars province.

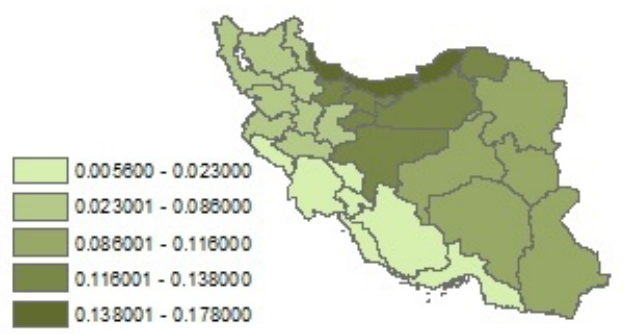

Source: own processing

Figure $2 \mathrm{~b}$ : The spillover effect with a $\% 1$ change in road stock in Mazandaran province.

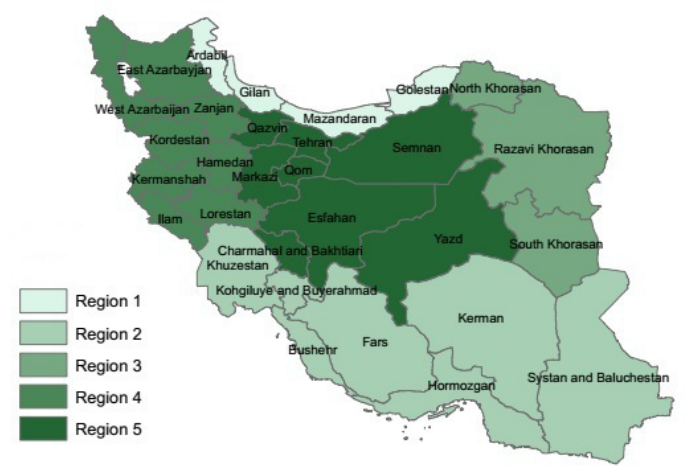

Source: own processing

Figure 3: Macro regions in Iran. 
The Table 3 reports the results of the estimation of the spatial Durbin model, and we can find that the coefficients of the labor employment, energy, capital stock are positive and significant. In the terms of the spatial lagged independent variables, the agricultural output is a positive function of public capital, and transportinfrastructure endowment in the neighboring provinces, also the spillover effects of labor is positive and significant. However, these estimators just provide an idea of interactions among provinces, thus we provide the sign and amount of the direct and indirect impacts in order to provide the accurate spillover effects, particularly associated with transport infrastructure in the Table 3. Using these alternative weight matrices to determine capital stock, energy spillover effect, we find that different spatial weight schemes have positive effect on agricultural output. The results also provide a reasonable estimate for the employment and energy factor, which indicates that labor and energy input growth has the largest impact on Iran real agriculture growth. This finding implies that the spillover effects played an important role in raising agricultural production because of transport network expansion. This expansion helps brings indirect externalities due to the development of transport network accessibility.

\section{Spillover effects at the regional level}

Considering mostly on the spillover effect of transport infrastructure (represented by $\varphi$ ), as can be determined distinctly in the Table 4, the elasticities of the spillovers differ considerably across regions in the entire time under study (the coefficients are, 0.15 and 0.09 for the region 1 and 5, respectively). When we compare our results for the three sub-term, we can observe that the changes in spillovers differ considerably among these regions. The neighboring transport investment will lead to positive effects in the region 4 (western region), and the output elasticity is, 0.06 (coefficient is statistically significant), which means the agricultural output will increase by $0.06 \%$ if the transport stock in the neighboring region increases by one percent at the second time while the road disbursement have no significant effect for the first time. For the region 2 (south region), the transport stock in the neighboring region has a positive external impact during the considering time. The regression results illustrate that the agricultural production elasticities of neighboring transport infrastructures for the three times are significant and positive (the coefficients are $0.16,0.16,0.18$ ). For the region 5 (central region), no significant spillovers can be found in time 2, but positive spillovers can be observed in the first time (the coefficient is 0.09). In the last time, positive externalities can be found (the coefficient is 0.10 ). In the region 1 (north region), the estimated coefficients of spillovers are 0.13 during 1980-1991, 0.17 during 1992-2003, 0.16 during 2004-2015, which means that the growth of the transport stock in neighboring regions actually had a positive impact on agricultural output in the north region all the time. For the region 3 (eastern region), the results show that agricultural output elasticities of neighboring transport investments are significant $(0.04,0.08,0.06)$, which indicates transport investment of neighboring regions had a positive impact on agricultural output in the eastern region all the time. Our paper adopted an advanced spatial Durbin model, considering both the spatial lagged dependent and independent variables: meanwhile the spatial spillovers from all the regions were measured in our study, which could make our estimators are more precise and persuasive. The different definitions of regions may also cause the incompatible results. In order to underline the spatial factors, five macro regions are classified considering the geographic position according to agricultural output level, which would make our estimate results of the spatial spillovers more realistic. The results from this study confirm the existence of spillover effects of transport infrastructure for the case of Iran. More specifically, changes in the spillovers between Iran's regions over time can be observed. For the aim of an in depth analysis in the regional difference in spatial spillovers, we will next investigate how the spillovers of transport infrastructure influence on agriculture output in Iran at the regional level. This study confirms the existence of spillover effects of transport infrastructure for the case of Iran. More specifically, changes in the spillovers between Iran's regions over time can be seen. For the aim of an in accurate analysis in the regional difference in spatial spillovers, we will next consider how the spillovers of transport infrastructure influence on agriculture output in Iran at the regional level. 


\begin{tabular}{|c|c|c|c|c|c|}
\hline Regions & Variables & $1980-2015$ & Time 1 & Time 2 & Time 3 \\
\hline Region1 & Capital & $0.164(14.56)^{* * *}$ & $0.055(16.62)^{* * *}$ & $0.176(10.82)^{* * *}$ & $0.148(11.37)^{* * *}$ \\
\hline \multirow[t]{16}{*}{ (North Region) } & employment & $0.233(15.46)^{* * *}$ & $0.291(12.31)^{* * *}$ & $0.241(14.96)^{*}$ & $0.312(12.30)^{* *}$ \\
\hline & energy & $0.362(25.16)^{* * *}$ & $0.32(21.17)^{* * *}$ & $0.373(17.58)^{* * *}$ & $0.256(16.44)^{* * *}$ \\
\hline & Land & $-0.075(3.45)^{* *}$ & $-0.126(4.86)^{* * *}$ & $-0.043(3.32)^{* *}$ & $-0.126(4.65)^{*}$ \\
\hline & Road Stock & $0.049(12.78)^{* * *}$ & $0.068(10.61)^{* * *}$ & $0.045(4.76)^{* *}$ & $0.076(14.75)^{* * *}$ \\
\hline & Export & $0.115(2.24)^{* *}$ & $0.087(1.45)$ & $0.064(2.87)^{* *}$ & $0.142(3.54)^{* * *}$ \\
\hline & GDP & $0.096(1.86)$ & $0.108(3.67)^{* * *}$ & $0.087(4.54)^{* * *}$ & $0.128(6.87)^{* * *}$ \\
\hline & $\rho$ & $0.263(10.42)^{* *}$ & $0.283(8.74)^{* * *}$ & $0.247(20.53)^{* * *}$ & $0.217(4.75)^{* *}$ \\
\hline & Capital.Splag & $0.187(5.27)^{* * *}$ & $0.012(2.98)^{* *}$ & $0.143(2.64)^{* *}$ & $0.045(2.26)^{*}$ \\
\hline & employment. Splag & $0.318(1.94)^{*}$ & $0.283(4.28)^{* * *}$ & $0.361(2.63)^{* *}$ & $0.293(6.54)^{* * *}$ \\
\hline & Energy.Splag & $0.284(4.32)^{* * *}$ & $0.365(5.97)^{* * *}$ & $0.345(2.64)^{* *}$ & $0.384(2.37)^{* *}$ \\
\hline & Land.Splag & $-0.016(4.46)^{* * *}$ & $-0.023(6.74)^{* * *}$ & $-0.028(2.44)^{* * *}$ & $-0.014(8.35)^{* * *}$ \\
\hline & Road Stock. Splag & $0.085(3.25)^{* * *}$ & $0.068(8.36)^{* * *}$ & $0.042(2.58)^{* *}$ & $0.092(6.48)^{* * *}$ \\
\hline & Export.Splag & $0.178(4.48)^{* * *}$ & $0.096(2.68)^{* *}$ & $0.164(1.75)$ & $0.215(9.47)^{* * *}$ \\
\hline & GDP.Splag & $0.084(9.70)^{* * *}$ & $0.057(1.53)$ & $0.093(4.63)^{* * *}$ & $0.126(4.52)^{* * *}$ \\
\hline & $\varphi$ & $0.156(10.28)^{* * *}$ & $0.136(2.46)^{* *}$ & $0.176(8.34)^{* * *}$ & $0.161(8.69)^{* * *}$ \\
\hline & Adj.R ${ }^{2} ;$ Log Likelihood & $0.546 ; 145.45$ & $0.745 ; 128.64$ & $0.456 ; 110.54$ & $0.610 ; 132.43$ \\
\hline Region2 & Capital & $0.212(8.34)^{* * *}$ & $0.155(7.15)^{* * *}$ & $0.078(3.84)^{* *}$ & $0.146(10.93)^{* * *}$ \\
\hline \multirow[t]{16}{*}{ (South Region) } & employment & $0.356(7.24)^{* * *}$ & $0.242(9.45)^{* * *}$ & $0.236(14.36)^{* * *}$ & $0.311(5.42)^{* * *}$ \\
\hline & energy & $0.361(12.54)^{* * *}$ & $0.424(15.63)^{* * *}$ & $0.413(2.36)^{* *}$ & $0.253(2.67)^{* *}$ \\
\hline & Land & $-0.087(14.46)^{* * *}$ & $-0.145(10.89)^{* * *}$ & $-0.091(16.75)^{* * *}$ & $-0.126(9.65)^{* * *}$ \\
\hline & Road Stock & $0.098(15.71)^{* * *}$ & $0.096(4.56)^{* * *}$ & $0.043(8.32)^{* * *}$ & $0.067(6.41)^{* * *}$ \\
\hline & Export & $0.175(8.54)^{* * *}$ & $0.096(12.85)^{* * *}$ & $0.164(2.64)^{* *}$ & $0.156(1.86)$ \\
\hline & GDP & $0.078(2.46)^{* *}$ & $0.054(1.63)$ & $0.108(4.56)^{* * *}$ & $0.114(2.23)^{* *}$ \\
\hline & $\rho$ & $0.185(8.54)^{* * *}$ & $0.196(2.34)^{* *}$ & $0.127(6.95)^{* * *}$ & $0.148(8.75)^{* * *}$ \\
\hline & Capital.Splag & $0.065(13.08)^{* * *}$ & $0.085(8.76)^{* * *}$ & $0.105(14.53)^{* * *}$ & $0.0951(5.43)^{* * *}$ \\
\hline & employment. Splag & $0.303(14.67)^{* * *}$ & $0.316(12.43)^{* * *}$ & $0.356(9.45)^{* * *}$ & $0.287(2.34)^{* *}$ \\
\hline & Energy.Splag & $0.345(2.62)^{* *}$ & $0.365(5.36)^{* * *}$ & $0.278(7.15)^{* * *}$ & $0.343(2.03)^{*}$ \\
\hline & Land.Splag & $-0.020(13.76)^{* * *}$ & $-0.145(21.64)^{* * *}$ & $-0.167(10.76)^{* *}$ & $-0.135(9.45)^{* * *}$ \\
\hline & Road Stock.Splag & $0.175(6.53)^{* * *}$ & $0.174(16.43)^{* * *}$ & $0.145(12.45)^{* * *}$ & $0.179(2.74)^{* *}$ \\
\hline & Export.Splag & $0.156(6.14)^{* * *}$ & $0.114(2.48)^{* *}$ & $0.063(13.93)^{* * *}$ & $0.084(3.79)^{* * *}$ \\
\hline & GDP.Splag & $0.086(2.18)^{* *}$ & $0.105(1.34)$ & $0.065(2.54)^{* *}$ & $0.147(6.85)^{* * *}$ \\
\hline & $\varphi$ & $0.168(7.34)^{* *}$ & $0.162(9.56)^{* *}$ & $0.164(2.46)^{* *}$ & $0.184(4.76)^{* * *}$ \\
\hline & Adj.R ${ }^{2}$, Log Likelihood & $0.845 ; 164.35$ & $0.657 ; 184.85$ & $0.762 ; 143.76$ & $0.754 ; 156.74$ \\
\hline Region3 & Capital & $0.176(12.43)^{* *}$ & $0.225(8.45)^{* * *}$ & $0.174(10.53)^{* * *}$ & $0.193(8.65)^{* * *}$ \\
\hline \multirow[t]{10}{*}{ (Eastern Region) } & employment & $0.315(13.87)^{* * *}$ & $0.269(3.67)^{* *}$ & $0.324(1.84)$ & $0.305(2.03)^{*}$ \\
\hline & enrgy & $0.346(9.32)^{* * *}$ & $0.302(10.76)^{* * *}$ & $0.357(9.53)^{* * *}$ & $0.317(12.35)^{* * *}$ \\
\hline & Land & $-0.08(10.49)^{* * *}$ & $-0.12(2.04)^{*}$ & $-0.04(4.56)^{* * *}$ & $-0.12(3.74)^{* *}$ \\
\hline & Road Stock & $0.046(16.86)^{* * *}$ & $0.065(10.75)^{* * *}$ & $0.046(2.67)^{* *}$ & $0.052(2.16)^{*}$ \\
\hline & Export & $0.071(2.68)^{* *}$ & $0.098(8.53)^{* * *}$ & $0.146(1.68)$ & $0.125(9.52)^{* * *}$ \\
\hline & GDP & $0.076(10.42)^{* * *}$ & $0.044(1.57)$ & $0.095(2.34)^{* *}$ & $0.085(1.48)$ \\
\hline & $\rho$ & $0.167(9.34)^{* * *}$ & $0.213(10.48)^{* * *}$ & $0.185(8.74)^{* *}$ & $0.246(8.33)^{* * *}$ \\
\hline & Capital.Splag & $0.115(2.56)^{* *}$ & $0.068(3.44)^{* *}$ & $0.092(1.80)$ & $0.108(3.78)^{* *}$ \\
\hline & employment. Splag & $0.385(7.35)^{* * *}$ & $0.316(14.52)^{* * *}$ & $0.306(20.45)^{* * *}$ & $0.308(14.36)^{* * *}$ \\
\hline & Energy.Splag & $0.357(12.56)^{* * *}$ & $0.348(10.84)^{* * *}$ & $0.329(6.52)^{* * *}$ & $0.311(9.83)^{* * *}$ \\
\hline
\end{tabular}

Note: t-statistics are given in parenthesis. Time1, Time2, Time3 represent respectively. Numbers of observations equals to numbers of provinces in each region multiplied by analysis period. Here, we calculated and reported the indirect effect (spillover effects) of transport infrastructure for each region in different times, represented by $\varphi .{ }^{*}$ Statistical significance at the $10 \%$ level. **Statistical significance at the $5 \%$ level. ***Statistical significance at the $1 \%$ level.

Source:

Table 4: Estimation of the Spatial Durbin model at the five selected region (to be continued). 


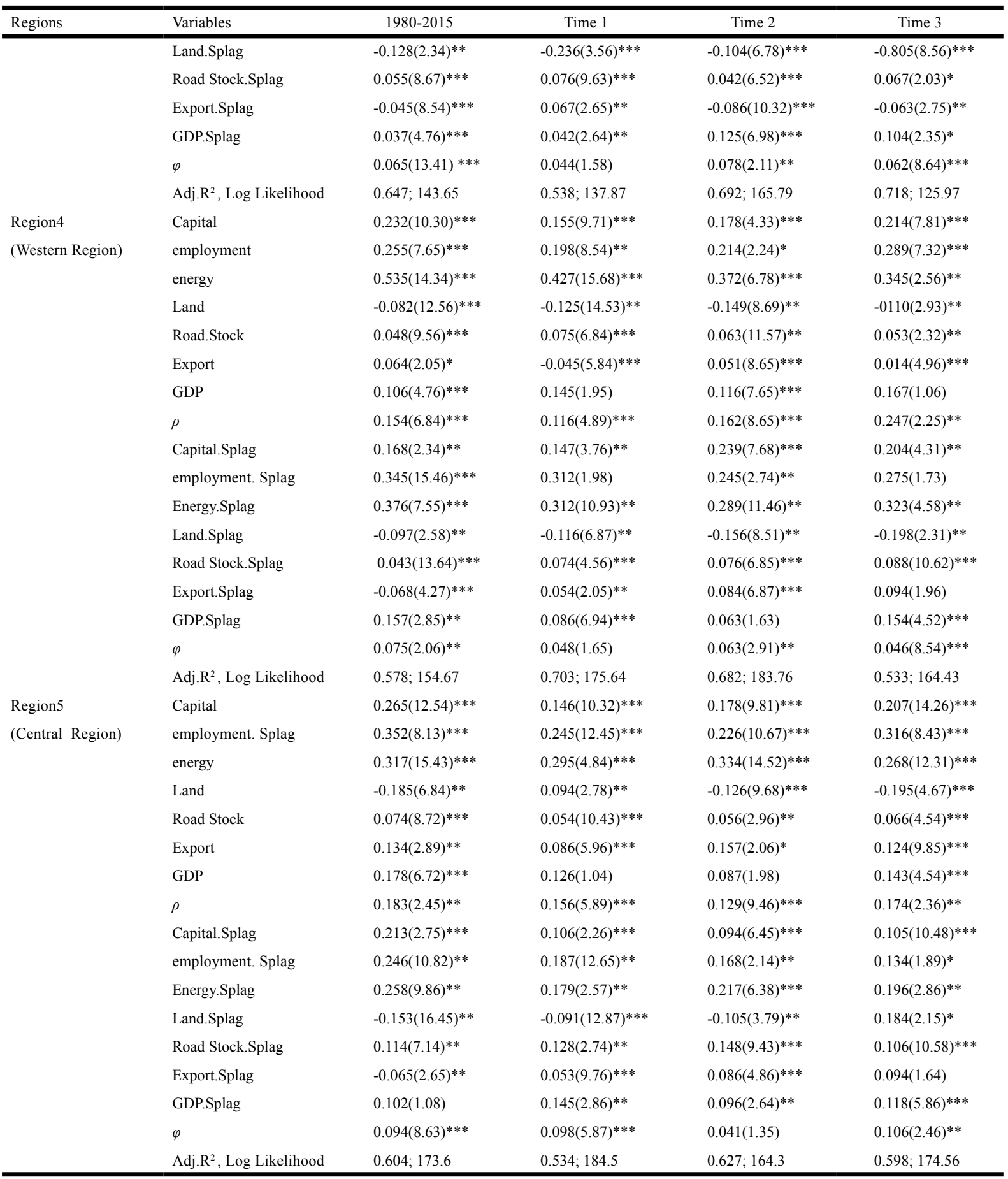

Note: t-statistics are given in parenthesis. Time1, Time2, Time3 represent respectively. Numbers of observations equals to numbers of provinces in each region multiplied by analysis period. Here, we calculated and reported the indirect effect (spillover effects) of transport infrastructure for each region in different times, represented by $\varphi$. *Statistical significance at the $10 \%$ level. **Statistical significance at the $5 \%$ level. ***Statistical significance at the $1 \%$ level.

Source:

Table 4: Estimation of the Spatial Durbin model at the five selected region (continuation).

\section{Conclusion}

The effects of transportation infrastructure on agricultural output for 30 Iran provinces from 1990-2015 are estimated in this study.
The SDM based on four different weight matrices is employed to evaluate spatial dependence in both dependent and independent variables. The positive spillovers exist at regional level, but the Iran's regions have considerable difference in their spatial 
spillovers across the different times under analysis. The existence of spatial externalities emerging from the contribution of transport infrastructure to agricultural output implies that the decision by altering investment patterns in the transport infrastructure relative.

\section{Acknowledgements}

This work was supported in the framework of the project with no. 40779 of the Ferdowsi university of Mashhad for the first author. She would like to acknowledge support from this project by Research Center of this university.

Corresponding authors:

Prof. Mohammad Reza Kohansal

Department of Agricultural Economics, Ferdowsi University of Mashhad, 9177948974, Iran

Phone:+985138805783,Email:kohansal@um.ac.ir

\section{References}

[1] Aschauer, D. A. (1989) "Is public expenditure productive?“", Journal of Monetary Economics, Vol. 23, No. 3, pp. 177-200. ISSN 0304-3932. DOI 10.1016/0304-3932(89)90047-0.

[2] Ball, V. E., Bureau, J. C., Nehring, R. and Somwaru, A. (1997) "Agricultural productivity revisited“ American Journal of Agricultural Economics, Vol. 79, No. 4, pp. 1046-1063. E-ISSN ISSN 14678276, ISSN 0002-9092. DOI 10.2307/1244263.

[3] Boarnet, M. G. (2002) "Spillovers and the locational effects of public infrastructure", Journal of Regional Science, Vol. 38, pp. 381-400. E-ISSN 1467-9787. DOI 10.1111/0022-4146.00099.

[4] Cantos, P., Gumbau, M. and Maudos, J. (2007) "Transport infrastructures, spillover effects and regional growth: evidence of the Spanish case“, Transport Reviews, Vol. 25, No. 1, pp. 25-50. E-ISSN 1464-5327, ISSN 0144-1647. DOI 10.1080/014416410001676852.

[5] Cohen, J. P. (2010) "The broader effects of transportation infrastructure: Spatial econometrics and productivity approaches", Transportation Research Part E: Logistics and Transportation Review, Vol. 46, pp. 317-326. ISSN 1366-5545. DOI 10.1016/j.tre.2009.11.003.

[6] Cohen, J. P. and Morrison Paul, C. J. (2004) "Public infrastructure investment, interstate spatial spillovers, and manufacturing costs“, The Review of Economics and Statistics, Vol. 86, pp. 551-560. E-ISSN 1530-9142, ISSN 0034-6535. DOI 10.1162/003465304323031102.

[7] Duranton, G. and Turner, M. A. (2012) "Urban growth and transportation“, Review of Economic Studies, Vol. 79, No.4, pp. 1407-1440. E-ISSN 1467-937X, ISSN 0034-6527. DOI 10.1093/restud/rds010.

[8] Elhorst, J. P. (2012) "Matlab software for spatial panels“, International Regional Science Review, Vol. 37, No. 3, pp. 389-405. DOI 10.1177/0160017612452429.

[9] Elhorst, J. P. (2013) "Spatial Panel Models“, In: Fischer, M . M., Nijkamp, P. (Eds), Handbook of regional science, Lavoisier, Paris, France, pp. 1637-1652. E-ISBN 978-3-642-23430-9, ISBN 978-3-642-23429-3. DOI 10.1007/978-3-642-23430-9_86.

[10] Fan, S. and Hazell, P. (2001) "Returns to public investments in the less-favored areas of India and China“, American Journal of Agricultural Economics, Vol. 83, No. 5, pp. 1217-222. E-ISSN 1467-8276, ISSN 0002-9092. [Online]. Available: http://www.jstor.org/stable/1244811. [Accessed: 20 Feb. 2018].

[11] Fingleton, B. and López-Bazo, E. (2006) "Empirical growth models with spatial effects“, Papers in Regional Science, Vol. 85, pp. 177-198. E-ISSN 1435-5957, DOI 10.1111/j.1435-5957.2006.00074.x.

[12] Haandrikman, K., Wissen, L. J. G. and Harmsen, C. N. (2010) "Explaining spatial homogamy. Compositional, spatial and regional cultural determinants of regional patterns of spatial homogamy in the Netherlands“, Applied Spatial Analysis, Vol. 4, pp. 75-93. E-ISSN 1874-4621, ISSN 1874-463X, DOI 10.1007/s12061-009-9044-6. 
[13] Holtz-Eakin, and D., Schwartz, A. E. (1995) "Spatial productivity spillovers from public infrastructure: Evidence from state highways“, International Tax and Public Finance, Vol. 2, No. 3, pp 459-468. E-ISSN 1573-6970, ISSN 0927-5940. DOI 10.1007/BF00872777.

[14] Jiwattanakulpaisarn, P., Noland, R. B. and Graham, D. J. (2010) "Highway infrastructure and private output: Evidence from static and dynamic production function models“, Transportmetrica, Vol. 7, No. 5, pp. 347-367. ISSN 1812-8602. DOI 10.1080/18128600903479638.

[15] Kemmerling, A. and Stephan, A. (2008) "The politico-economic determinants and productivity effects of regional transport investment in Europe“, EIB Papers 7/2008, European Investment Bank (EIB), Economic Department.

[16] Lee, L. F. and Yu, J. (2010) "Estimation of spatial autoregressive panel data models with fixed effects“ Journal of Econometrics. Vol. 154, No. 2, pp. 165-185. ISSN 0304-4076. DOI 10.1016/j.jeconom.2009.08.001.

[17] LeSage, J. P. and Pace, R. K. (2009) "Introduction to Spatial Econometrics“, CRC Press, Taylor\& Francis Group, Boca Raton, FL, 374 p. ISBN 9781420064247.

[18] Moreno, R. and López-Bazo, E. (2007) "Returns to local and transport infrastructure under regional spillovers“, International Regional Science Review, Vol. 30, No. 1, pp. 47-71. DOI 10.1177/0160017606296728.

[19] Munnell, A. and Cook, L. M. (1990) "How does public infrastructure affect regional economic performance?“", New England Economic Review, No. Sept/Oct., pp. 11-33.

[20] Ozbay, K., Ozmen-Ertekin, D. and Berechman, J. (2007) "Contribution of transportation investments to county output", Transport Policy, Vol. 14, No. 4, pp. 317-329. ISSN 0967-070X. DOI 10.1016/j.tranpol.2007.03.004.

[21] Pereira, A. M. and Andraz, J. M. (2006) "Public investment in transportation infrastructures and regional asymmetries in Portugal“, Annals of Regional Science, Vol. 40, pp. 803-817. E-ISSN 1432-0592, ISSN 0570-1864. DOI 10.1007/s00168-006-0066-6.

[22] Pereira, A. M. and Roca-Sagales, O. (2001) "Infrastructures and private sector performance in Spain“, Journal of Policy Modeling, Vol. 23, No. 4, pp. 371-384. ISSN 0161-8938. DOI 10.1016/S0161-8938(01)00068-0.

[23] Pereira, A. and Roca-Sagales, O. (2003) „Spillover effects of public capital formation: evidence from the Spanish regions“, Journal of Urban Economics, Vol. 53, No. 2, pp. 238-256. ISSN 0094-1190. DOI 10.1016/S0094-1190(02)00517-X.

[24] Tong, T. T., Yu, T. H. E., Cho, S. H., Jensen, K. and De La Torre Ugarte, D. (2013) "Evaluating the spatial spillover effects of transportation infrastructure on agricultural output across the United States“, Journal of Transport Geography, Vol. 30, pp. 47-55. ISSN 0966-6923. DOI 10.1016/j.jtrangeo.2013.03.001. 